\title{
Research
}

\section{Supporting and Enhancing Development of Heterogeneous Ecological Knowledge among Resource Users in a Kenyan Seascape}

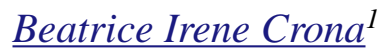

\begin{abstract}
The heterogeneous nature of even small communities has been acknowledged, yet how such heterogeneity is reflected in local ecological knowledge (LEK) among groups of resource users in a community is poorly studied. This study examines the ecological knowledge held by fisher groups using differing gear and operating in different subsystems of a coastal seascape in south Kenya. Knowledge is compared to that of nonfishing groups and is analyzed with respect to the scales of ecological processes and disturbances affecting the ecosystem to identify mismatches of scale between local knowledge and ecological processes, as well as points of convergence upon which emerging scientific and local community information exchange can build and develop. Results reveal significant differences in the level and content of ecological knowledge among occupational categories with respect to the scale and nature of ecological interactions in the seascape. Nonfishing related groups were marked by consistently low levels of knowledge and understanding of all seascape components and processes. Gear-defined fisher groups appeared linked, through fishing methods, to specific functional groups defined by trophic level, although acknowledgment among users of trophic links and ecosystem effects were not always apparent. Knowledge appeared to be largely related to maximization of resource extraction rather than reflecting deep understanding of ecological processes and causal links. Demographic changes and erosion of traditional management systems may partly explain this. Based on the results it is suggested that future investments geared at enhancing socioeconomic standards, e.g., through investment in improved gear, run the risk of further propelling the system down the poverty trap through habitat degradation and stock depletion, if not simultaneously combined with support for development and enhancement of existing LEK.
\end{abstract}

Key Words: heterogeneous; local ecological knowledge (LEK); seascape; Kenya; East Africa; artisanal fishery

\section{INTRODUCTION}

It has been argued that sustainable use of ecosystems depends on ecological knowledge, flexible institutions, and adaptive organizations (e.g., Ostrom 1990, Olsson and Folke 2001, Ostrom 2005). Simultaneously, community based management (CBM) is hailed across many parts of the world as a potential solution in which past conventional governance has failed (Hulme and Murphree 1999, Goldman 2003, WRI 2005). CBM prescribes the active involvement of stakeholders, but often fails to recognize the heterogeneous nature of small communities (Agrawal 1997). A heterogeneity may also be reflected in the local ecological knowledge (LEK) harbored by different user groups (Ghimire et al. 2004). LEK may be a mix of scientific and practical knowledge; it is site specific and often involves a belief component (Olsson and Folke 2001). The idea of using such knowledge to enhance ecosystem management is well established (Berkes et al. 1995, Johannes 1998, Scoones 1999, Colding and Folke 2001, Drew 2005) and has been successfully implemented in several cases (Olsson and Folke 2001, Becker and Ghimire 2003, Aswani and Hamilton 2004). However, environmental governance depends on good, trustworthy information about the internal dynamics of the resource system (Dietz et al. 2003), and this information must match the scale of environmental events and decisions (Young 2002). In Kenya, initiatives toward participatory monitoring for the management of coastal resources have recently emerged (Obura et al. 2002b) with the aim of 
including local fishermen in monitoring and management (Alidina 2005).

In the coastal fishing community of Diani-Chale, south Kenya, Glaesel (2000) found that in spite of cultural and religious homogeneity, social group identification was strongly based on occupation, and it, in turn, was related to the use of specific fishing gear. Furthermore, in an artisanal fishery setting, gear type will dictate where the principal fishing effort is spatially located in the seascape, thus, likely affecting the type and scale of ecological knowledge accumulated. Therefore, this study sets out to describe and compare the ecological knowledge held by groups using differing gear and operating in different subsystems of a seascape on the south Kenyan coast. Furthermore, local ecological knowledge held by the community is analyzed with respect to the scales of ecological processes and disturbances affecting the ecosystem to identify mismatches of scale between local knowledge and ecological processes, as well as points of convergence upon which emerging scientific and local community information exchange can build and develop.

Although authors have argued for the potential complementarities between LEK and science in resource management (Moller et al. 2004); any fruitful combination of the two knowledge systems requires, as a first step, an inventory of existing knowledge to identify points of convergence as well as gaps of information. Existing knowledge and understanding of ecological systems among user groups will also provide a stronger incentive for sustainable management of the resource. In addition, since institutional reform is argued by some to be a slow process (North 1990, Putnam 1993), it would seem feasible to build emerging local and scientific collaboration and information exchange on already existing institutions. Using North's (1990) broad definition of institutions, this paper argues that the social groups among fishermen, defined by gear (Glaesel 2000), constitute a type of informal institution as well as a framework within which LEK is generated and maintained. Although abundant studies of LEK exist, few have attempted to systematically compare the knowledge of user groups within the same social-ecological system (Ghimire et al. 2004), and studies of LEK relating to coastal resources in general, and East Africa in particular, are scant (Tobisson et al. 1998, de La Torre-Castro and Rönnbäck 2004). Considering the emerging interest in involving local stakeholder groups in management as monitors based on their knowledge (Obura et al. 2002a), a good understanding of the distribution of LEK among members of the fishing community would seem a valuable base on which to build future management progress. This paper attempts to add to this understanding by systematically comparing LEK across groups of resource users.

\section{DEFINITIONS}

In this paper, local ecological knowledge (LEK) is defined according to Olsson and Folke (2001) as knowledge held by a specific group of people about their local ecosystems. As noted above, LEK may be a mix of scientific and practical knowledge, it is site specific, and often involves a belief component. Consequently, LEK differs from traditional ecological knowledge (TEK) in that it often lacks the dimension of historical and cultural continuity (Olsson and Folke 2001). Such is the case in this study in which traditional belief systems have gradually been replaced by Islam (Glaesel 1997), and local communities have experienced a large influx of immigrants in recent decades.

Ecosystem management is a systems approach to the management of natural resources (Christensen et al. 1996). Its primary goal is the sustainable use of resources such that vital ecological functions and processes are maintained and that ecological functioning depends on ecosystem structure and diversity, that ecosystems are spatially and temporally dynamic, and the importance of adaptive learning for effective resource policy development in response to such dynamics. Building on these ideas, Dale et al. (2000) defined five principles as important for ecosystem management: time, species, place, disturbance, and landscape. As in Olsson and Folke (2001), these principles are used here for comparison with the knowledge of local resource users to analyze and discuss differences in the temporal and spatial scales of ecological knowledge held by different user groups about their resource base. This resource base comprises the interlinked coastal ecosystems of coral reefs, seagrass beds, and mangroves, and will hereafter be referred to as the coastal seascape (after Ogden and Gladfelder 1983). 


\section{CULTURAL AND INSTITUTIONAL CONTEXT}

The area of focus is a Kenyan rural fishing village located $50 \mathrm{~km}$ south of Mombasa (Fig. 1). It has approximately 200 households and an estimated 1000 inhabitants. The ecological system is characterized by mangroves covering 615 ha with mudflats and seagrass meadows in the shallow part of the lagoon in turn, sheltered from wave impact by shallow reefs at the mouth of the bay (Fig. 2). The use of resources in the village is centered on fishing and to some degree the use of mangroves for poles and firewood. Other nonforest products are also taken from mangroves, but government restrictions, e.g., a cutting ban, has periodically impeded extraction of wood products by the local people (Dahdouh-Guebas et al. 2000). A majority of households depend primarily on fishing for their livelihoods. The local artisanal fishery is based on gear such as seine nets, different types of gillnets, spearguns, and handlines; methods that have all been found to be spatially separated on a local geographical basis (Obura et al. 2002b, Fig. 2). Such spatial differentiation is a feature of many artisanal fisheries (Johannes 1981) and is likely to have an effect on the interactions among users as well as the local ecological knowledge harbored by user groups (Davis et al. 2004). The local fishery focuses on finfish, but also includes various crustaceans and mollusks such as juvenile penaeid shrimps, fished only by women and sold at local markets. Data collected in a parallel study (Crona and Bodin, personal observation) shows that $25 \%$ of households receive remittances, i.e., economic subsidies from kin outside the village, in the form of money or commodities, and $75 \%$ of these are represented by young (20-30 yr) and old (50+ yr) households, based on the age of the head of household. In addition, $37 \%$ of households are recent immigrants, and the majority of these originate from Tanzania, to which they return on a regular basis. Many Tanzanian fishermen reside in the village on a semi-permanent basis such that they return to their homeland during seasons of low fishing activity. Migration is linked to economic factors and kinship ties. During high season, migrating fishermen return to the study area to fish and are often assisted with travel expenses and permits by local middlemen, i.e., fishmongers, operating out of the village. At the same time, kinship ties play a significant role in who is recruited to come along as crew for the duration of the season. The social ties governing patterns of migration and fishing pressure in the area are treated in detail in a forthcoming paper.

\section{Livelihood strategies under changing conditions}

The coast of eastern Africa has a long history of influences from foreign cultures such as India, Malaysia, and Greece. Today, the population of coastal Kenya comprises two main ethnic groups: the Mijikenda of Bantu origin and the Swahili who are of mixed Bantu, Asian, and Arabic descent (King 2000). The Mijikenda comprise nine tribes, of which Digo is the predominant ethnicity of inhabitants in the study area. Historically, the Mijikenda were farmers and started their relation to the Swahilis as traders of agricultural products, but as a consequence of colonial land access policies and politics in the early 20th century, the Digo were forced to abandon traditional shifting cultivation and convert to Islam, which led to a need to diversify their livelihoods (Ng'weno 1995).

Since Digo people developed their dependence on fishing over a relatively short period in response to declining land access, it is argued by some that traditional institutions used to govern their fishing related activities were not sufficiently embedded to persist through changing social and ecological conditions (King 2000). This is supported by Glaesel (2000), describing the undermining of local institutions for managing the common fishery in the early to mid 1900's, as a combination of factors, including the strife of the Kenyan government to develop the marine fishing industry, the parallel rise of coastal tourism attracting large numbers of unskilled labor, and skilled, knowledgeable fishermen who have abandoned the occupation for more lucrative ventures. The vast majority of newcomers, primarily young men seeking employment, were not absorbed by the tourist industry and turned to speargun fishing as a mode of self-employment (Glaesel 1997). This fishing technique required low-capital gear investment and was freed from the apprenticeship and kinship ties traditionally associated with other gear types. Another strain on the traditional management system has been the dramatic influx of Tanzanian fishermen, after the 1964 overthrow of the ZanzibarPemba government, resulting in large seine crews establishing more or less semi-permanent operations along the Kenyan coast (Glaesel 1997). Records show that although currently classified as 
Fig. 1. Map of the study area with the target community indicated in the inset of the left hand corner. The area is located on the southern Kenyan coast at $4^{\circ} 25^{\prime} \mathrm{S}$ and $39^{\circ} 50^{\prime} \mathrm{E}$, approximately $50 \mathrm{~km}$ south of Mombasa.

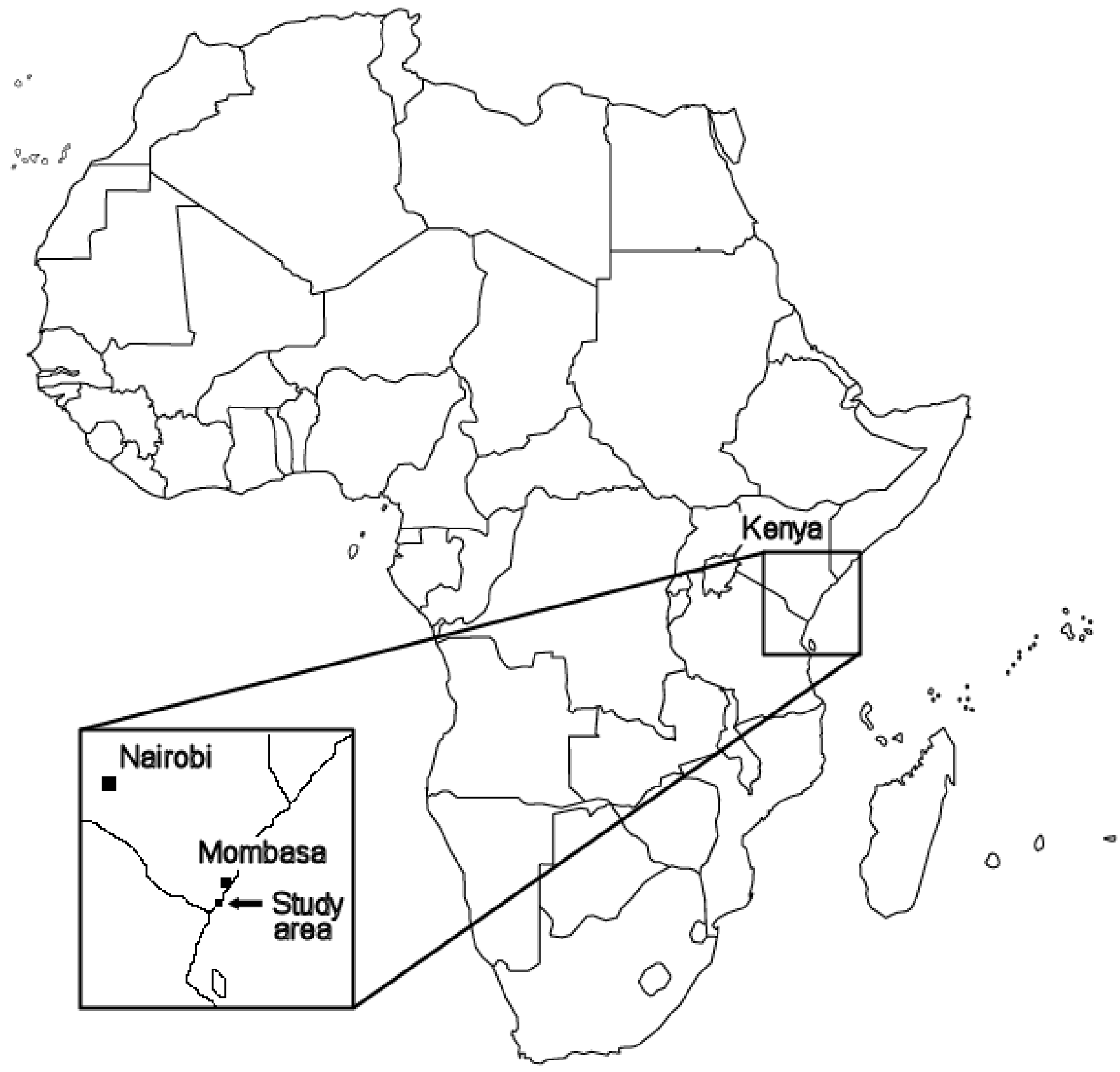

illegal, spearguns and seines have increased in proportion to other fishing methods in the area (McClanahan et al. 1997, Glaesel 2000).
Current management and policy environment

Gradual weakening of traditional governance structures, coupled with a national top-down view of legislation with heavy focus on regulatory 
Fig. 2. Map of the coastal seascape in focus. The respective distribution of mangroves, mudflats, seagrass beds, and reefs is indicated. The area of primary fishing effort for each fishing related occupational category is marked with dotted lines showing the geographical distribution of fishing areas at a local scale. The occupational categories associated with each area are indicated in the figure.

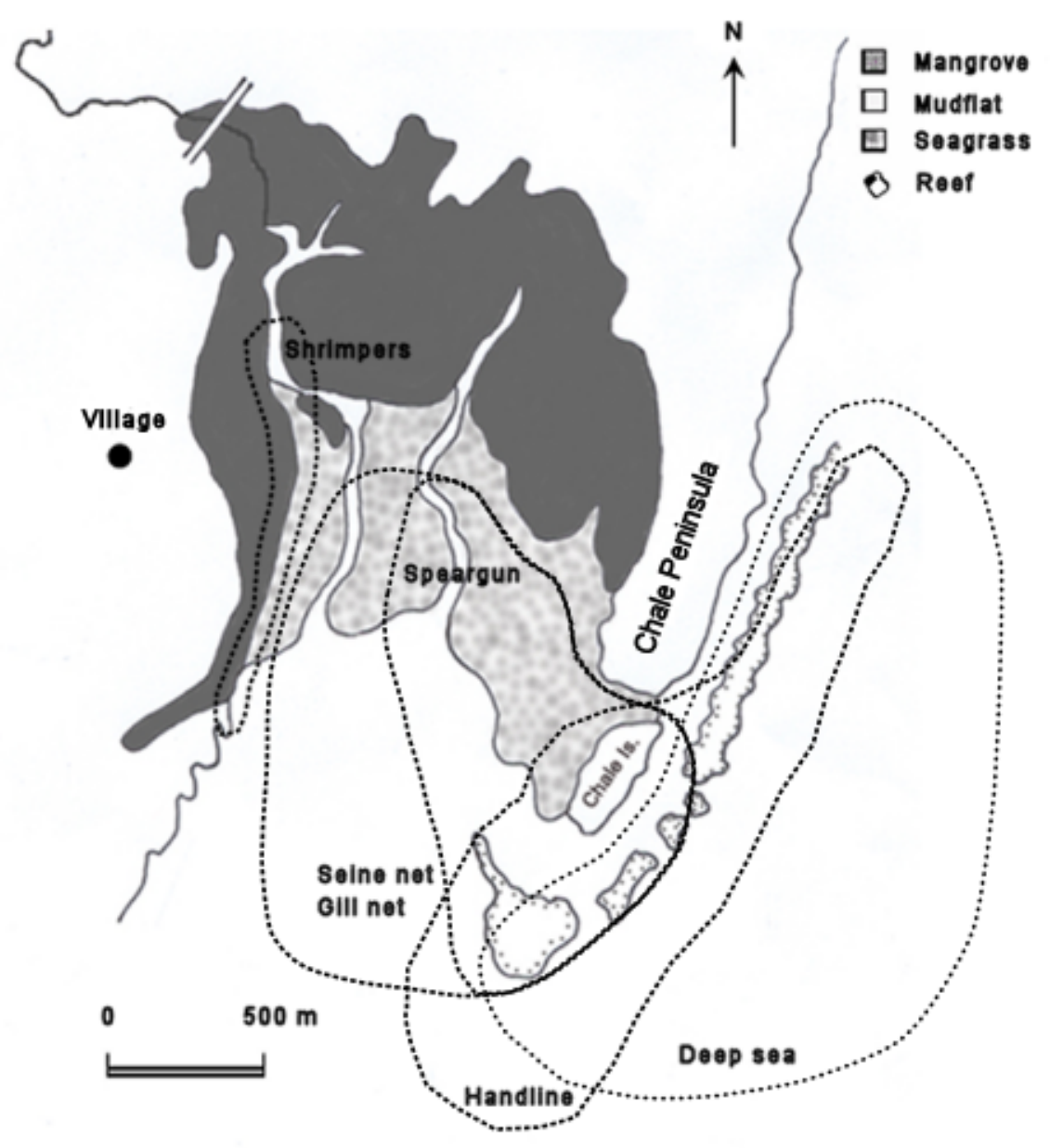

measures but without sufficient capacity for enforcement (GOK 1991, 2001), has led to a situation in which the inshore fishery along the southern Kenyan coast is a virtually open access system (Alidina 2005). This has led to overfishing and depletion of inshore stocks (Ochiewo 2004). Mangroves have also suffered, as intensive mangrove timber extraction reached a maximum in the 1970's, leading the government to impose a mangrove cutting ban, which has since been in force on and off. The lifting of this ban is currently under review (Kwale District Forestry Officer, personal communication), and in the Forest Act (GOK 1994) community involvement in management of resources is suggested as a future goal. In response to the fisheries situation, recent initiatives have been taken, for example, by forming the Diani Chale Management Trust (DCMT) just north of the area of focus in this study (Fig. 1). This umbrella group (Becker and Ostrom 1995) includes representatives from local community-based organizations, community leaders, local administration, and 
government agencies, and has set as a goal to be the coordinator of Integrated Coastal Area Management in the area. The exact role of DCMT in fisheries management has yet to be articulated, but information about the state of the fishery on a dayto-day basis is suggested to greatly improve the potential for flexible and sustainable management of the resource (Alidina 2005). The fact that they spend long hours actively observing the resource would seem to make fishermen well-suited to undertake such monitoring, bearing in mind, however, that without institutions allowing fishers to also monitor the behavior and extraction of others, few incentives would exist for them to accurately report their actions or the status of the resource.

\section{METHOD}

The aim of this paper is to investigate the existence of local ecological knowledge of different user groups, i.e., occupational categories, based on their primary gear type (Fig. 2). To collect data on ecological knowledge, focus group and individual interviews were conducted. Thirteen groups were interviewed, complemented with 19 individual interviews of seven middlemen, i.e., fishmongers, six local businessmen, four farmers and two retired fishermen/elders, from March to May in 2004 and from September to October in 2005. Each focus group contained four to six participants, interviews lasted between $2-2 \frac{1}{2} \mathrm{~h}$, and groups were selected based on interviews with the village chairman and fishermen at the local landing site. A total of 62 persons participated in the focus groups. In most cases, a captain was approached and asked to participate along with the members of his crew (see Appendix 1 for additional details on respondent selection).

A segmented sampling design was used with replication of each category in the following way; three groups of deep-sea fishermen, seinenet fishermen and gill-net fishermen, three groups of women who fish shrimp, and one group each of handline and speargun fishermen, as these men work primarily alone, and not enough individuals were resident in the village to gather more than one group of each category. A more detailed description of occupation category attributes and respondent selection is given in Appendix 1. Individual interviews were similarly analyzed and compared based on occupational category of respondents. To compare knowledge among these categories, a semi-structured interview guideline was used (Morgan 1998). The start of each discussion centered on general topics such as why they had chosen their profession, how long they had been doing it, as well as their thoughts on knowledge transfer to younger generations. The main discussion focused on two topics: (1) their knowledge of species and ecological processes in the bay and (2) acknowledgment of changes in the ecosystem over time and understanding of ecological processes and links among seascape components. Throughout the discussion, map drawing and timelines were used as aids for the groups to discuss the issues at hand. Knowledge was determined as representative for the gear category, and was included in the subsequent analysis only if mentioned at least three times by separate groups (see Davis and Wagner 2003 for further methodological discussion). Swahili folk systematics for fish and other target organisms is largely underdifferentiated, meaning that one folk generic taxon refers to several scientific species of the same genus (Berlin 1973). Therefore, species are only discussed when their identification has been clearly established through pictures or live specimens in conjunction with interviews. All interviews were conducted in Kiswahili (see Appendix 1 for details on interview setup and translation).

\section{RESULTS}

Interview discussions showed the fishing profession to be viewed largely as a social cushion absorbing young and old, as unemployment is widespread. This contributes to the fishing occupation loosing its former status as a profession associated with high knowledge and experience. Analysis of knowledge furthermore revealed significant differences in the level and content of ecological knowledge among occupational categories with respect to the scale and nature of ecological interactions in the seascape. Nonfishing related groups were marked by consistently low levels of knowledge and understanding of all seascape components and processes. Gear-defined fisher groups appeared to be linked, through fishing methods, to specific functional groups defined by trophic level although acknowledgment among users of trophic links and ecosystem effects were not always apparent. Below follows a detailed account of the analysis under each theme outlined above. 


\section{The importance of ecological knowledge and knowledge transfer}

The majority of respondent groups deemed it important to pass on their knowledge to their children. There is a tradition of children accompanying their parents and learning by observation and participation, rather than theoretical or formal instruction, for fishing and farming related activities. Similarly, new crew members are often trained by their captains or elder crew members. Although the knowledge is stressed as important, most fisher groups state that formal schooling should be prioritized and only in cases in whch this does not lead to a regular job should fishing be pursued. Fishing is, thus, viewed as a cushion to fall back on when other modes of income have failed and can also function as a social support network, providing young people alternatives to engaging in substance abuse or criminal activity. Such attitudes bear witness to the declining status of the fishing profession also observed by Glaesel $(1997,2000)$.

\section{Knowledge of species and ecological processes in the bay}

This section was introduced by asking participants to list the species judged to be most valuable to them, taking into consideration the anticipated price at sale, the perceived abundance, and the proportional importance of the species to their daily catch. This was to establish if the target species of the groups differed and if such differences could have any bearing on their subsequent knowledge of the ecological system in which they operate.

The deep-sea and seine-net fishermen target similar species consisting primarily of larger pelagic species such as Scombrids, e.g., mackerels and tunas, and Carangids, e.g., kingfish, but also more reef-bound genera such as Caesio sp., Lethrinus sp., Lutjanus sp., and Siganus sp. The fish targeted by seine-net crews included a higher proportion of lagoon and reef-bound species (Table 1). Even though seine-net fishermen have a stronger focus on the inner parts of the reef and the lagoon, whereas deep-sea fishermen concentrate on stocks well outside the reef, there was considerable overlap in the target areas (Fig. 2).

The remaining groups differed considerably in their primary target species with handline fishermen focusing on large predators such as sharks, whereas speargun fishermen selectively catch large individuals of many species on the reef including Carangids, Scombrids, and Siganids (Table 1). Women target juvenile shrimp and catch fish only as by-catch.

In-depth discussions on the ecology, e.g., spawning, ontogenetic migration, trophic groups etc., of each target species were conducted to get an appreciation of the level of detail in ecological knowledge that the groups held about these species (Fig. 3). Deepsea fishermen generally had a very good conception of the locations in which targeted species or taxa spawn, whether they migrate to inshore nursery areas, and if they migrate regionally according to season. However, when asked about feeding habits, only $65 \%$ of answers related to their listed species were in line with scientific information (Froese and Pauly 2004). Seine-net, gill-net, handline, and speargun fishermen, similarly, had a fair knowledge of the ecology of their target species, and over $80 \%$ of their answers of fish feeding habits agreed with Fishbase information. Women fishing groups, i.e., shrimpers, target only juvenile penaeid shrimps, and other listed species are merely by-catch. Answers showed a fair agreement with known dietary information for juvenile shrimp (67\%), but dietary information on by-catch species to corroborate answers was difficult to obtain as little information exists on juveniles of these species. Discussions with women also revealed a fragmented understanding of penaeid ecology, and knowledge of ecology for by-catch species was poor. Since juvenile shrimps are transparent, the women had observed that their guts were often brown and, hence, it was suggested that they ate mud. Similarly, in the majority of focus groups, detritivorous species such as crustaceans, molluscs, and fish, were described by respondents as mudfeeders. Although most respondents could not give an accurate account of whether animals ingested the actual mud or, rather, organisms living in the mud. Such statements were considered as at least reflecting an understanding of the main dietary source of the target species. Discussions on animal feeding also revealed that respondents' knowledge of diets was based primarily on observations of gut content rather than direct observations of feeding.

Knowledge among middlemen included an understanding of the mangrove, seagrass, and reef components at generally high levels of detail. However, this occupational category consisted of 
Table 1. Species targeted by fishermen using differing gear types and operating within distinct subsystems of the coastal seascape. Functional groups of target organisms are based on trophic level. Dietary preferences and trophic level are based on Froese et al. (2004). 1 = reef associated $2=$ seagrass associated.

\begin{tabular}{|c|c|c|c|c|c|c|}
\hline User group & Deep Sea & Seine net & Gillnet & Handline & Speargun & Shrimpers \\
\hline $\begin{array}{l}\text { Species targ- } \\
\text { eted }\end{array}$ & $\begin{array}{l}\text { Carangidae }(\mathrm{P}) \\
\text { Scombridae }(\mathrm{P}) \\
\text { Selar sp. }(\mathrm{P}) \\
\text { Squid }(\mathrm{P}) \\
\text { Lethrinus } \mathrm{sp} .(\mathrm{BP}) \\
\text { Scaridae }(\mathrm{H}) \\
\text { Siganus } \mathrm{sp} .(\mathrm{H})^{1} \\
\text { Caesio sp. }(\mathrm{Pl}) \\
\text { Hyporamphus } \mathrm{sp} . \\
(\mathrm{O})\end{array}$ & $\begin{array}{l}\text { Carangidae }(\mathrm{P}) \\
\text { Caranx } \mathrm{sp} .(\mathrm{P}) \\
\text { Scombridae }(\mathrm{P}) \\
\text { Selar sp. }(\mathrm{P}) \\
\text { Sphyraena } \mathrm{sp} . \\
(\mathrm{P}) \\
\text { Squid }(\mathrm{P}) \\
\text { Strongylura sp. } \\
(\mathrm{P}) \\
\text { Lutjanus argen- } \\
\text { timaculatus }(\mathrm{BP}) \\
\text { Lethrinus } \mathrm{sp} . \\
\text { (BP) } \\
\text { Pomadasys } \mathrm{sp} . \\
\text { (BP) } \\
\text { Mugilidae }(\mathrm{H}, \\
\mathrm{P}) \\
\text { Siganus sp. }(\mathrm{H}) \\
1,2\end{array}$ & $\begin{array}{l}\text { Sphyraena sp. (P) } \\
\text { Strongylura sp. } \\
\text { (P) } \\
\text { Gerres sp. }(\text { BP) } \\
\text { Lethrinus harak } \\
\text { (BP ) } \\
\text { Siganus sp. }(\mathrm{H})^{1,2} \\
\text { Mugilidae }(\mathrm{H}, \mathrm{P}) \\
\text { Chanos chanos } \\
(O)\end{array}$ & $\begin{array}{l}\text { Carcharinus } \\
\text { melanopterus }(\mathrm{P}) \\
\text { Makaira indica } \\
(\mathrm{P}) \\
\text { Scombridae }(\mathrm{P}) \\
\text { Sphyraena } \mathrm{sp} \text {. } \\
(\mathrm{P}) \\
\text { Rhyncobatus } \\
\text { djiddensis }(\mathrm{BP})\end{array}$ & $\begin{array}{l}\text { Caranx sp. } \\
(\mathrm{P}) \\
\text { Scombridae }(\mathrm{P}) \\
\text { Squid }(\mathrm{P}) \\
\text { Scaridae }(\mathrm{H}) \\
\text { Siganus } \mathrm{sp} . \\
(\mathrm{H})^{1} \\
\text { Lobster }(\mathrm{O})\end{array}$ & $\begin{array}{l}\text { Conch shells (D) } \\
\text { Juvenile } \\
\text { Penaeidae (D) }\end{array}$ \\
\hline
\end{tabular}

Functional Pelagic/demersal groups predators $(\mathrm{P})$ Benthic predators (BP) Herbivores $(\mathrm{H})$ Planctivores $(\mathrm{Pl})$ Omnivores (O)

Seascape su- Outer reef slope bsystem
Pelagic/demersal Pelagic/demersal predators $(\mathrm{P}) \quad$ predators $(\mathrm{P})$ Benthic pred (BP) Herbivores $(\mathrm{H})$ Herbivores $(\mathrm{H})$ Planctivores (Pl) Planctivores (Pl) Omnivores (O)
Apex predators Pelagic/deme- Detritivores (D) (P) Benthic pred (P) (BP) Herbivores (H) Omnivores (O)
Reef and Lagoon lagoon
Outer reef Reef and slope, reef, and lagoon lagoon
Intertidal seagrass beds and mangrove channels respondents with various backgrounds; all former fishermen but with varying experience and using differing gear. This was reflected in their equally heterogeneous knowledge, such that respondents' knowledge tended to be similar in detail to that of the gear-defined fisher group to which they previously belonged.

\section{Acknowledgment of changes in the ecosystem over time and understanding of ecological processes and links among components in the system}

Six of eleven groups indicated that there had been a decline in fish or shrimps over the years. The 
Fig. 3. Relative difference in local ecological knowledge among different occupational groups operating in the target community. Knowledge is divided into three categories based on the three recognized subcomponents of the coastal seascape; mangrove, seagrass, and reef. Knowledge of different groups for each subcomponent is represented as the relative difference of their level of knowledge compared to an estimated average level of knowledge for all groups, i.e., the baseline in the figure. Thus, the bars represent each group's knowledge in relation to other groups. Amount of knowledge, for each occupational category, is ranked based on the expressed level of detail of ecological components and processes. Although groups may be represented as having equal levels of knowledge in terms of detail, the actual content of the knowledge may at times be related to different species depending, for example, on which species are primarily targeted by a specific group.

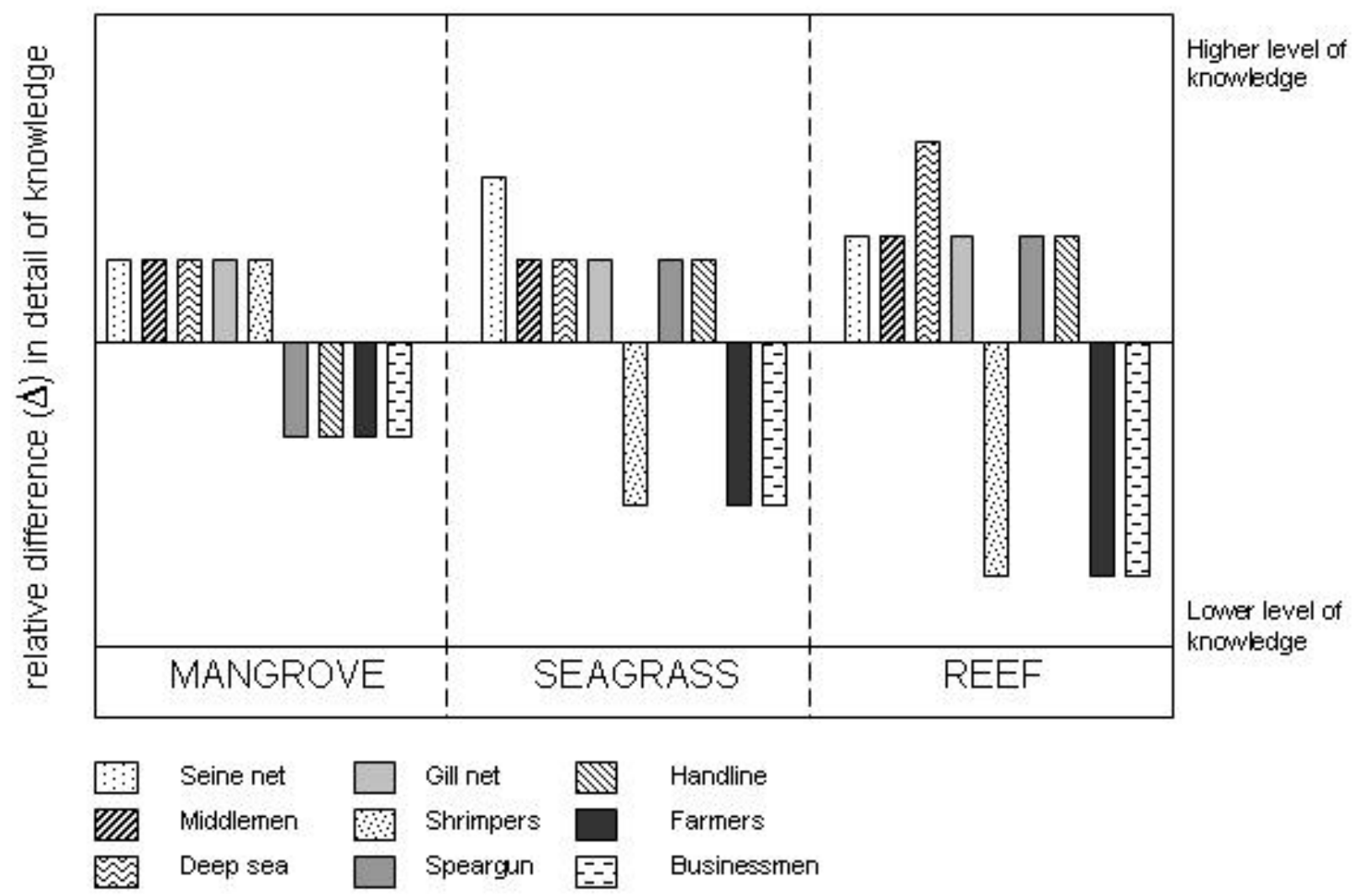

remaining groups, of which all were deep-sea and seine-net crews, did not perceive any such change in catches. Consequently, these net fishermen seem to be less affected by the decline in fish, at least in their own opinion. All of the groups of women indicated a drastic decline in shrimp catch over the years. Neither group explicitly stated that there are now less shrimp, but they suggested that lower catches are due to the larger number of fishing groups using the area, some of which are inexperienced and disturb and scare away the shrimp. Nonetheless, per-capita shrimp catches 
Table 2. Local ecological knowledge among groups of resource users, i.e., occupational categories, using different gear types and operating in distinct but overlapping subsystems of a coastal seascape in Kenya. The knowledge is classified and related to the ecological principles defined by Dale et al. (2000a). Occupational category is based on main gear type used and groups are listed in this column according to the ecological knowledge they were found to possess. * groups exhibiting much less detailed understanding of links and processes 1 Differences in scale of the fish migrations acknowledged by different groups. Deep Sea, Gillnet fishermen and Middlemen all perceive migrations on a local and regional scale, whereas Seine net fishermen spoke only of fish migrations at a local scale in the bay.

Ecological principle $^{\mathrm{a}} \quad$ Knowledge of resource users reflecting each principle Groups possessing this
knowledge

Time

Ecological processes function at different time scales, some long, some short; and ecosystems change over time.

$\begin{array}{ll}\text { A clear understanding of the effects of clear-cutting of } & \text { Shrimpers } \\ \text { mangroves on related systems } & \text { Deep Sea } \\ \text { Speargun } & \text { Gillnet } \\ & \text { Middlemen } \\ & \text { Farmers* } \\ & \text { Businessmen* } \\ & \\ & \text { Deep Sea } \\ \text { Notions among respondents that fish stocks migrate } & \text { Seine net } \\ \text { along the coast and that such patterns are affected by } & \text { Gillnet } \\ \text { seasonal monsoons }{ }^{1} & \text { Middlemen }\end{array}$

Knowledge of the keystone function of mangroves in coastal biological, hydrological and geomorphologic processes in the form of nursery habitats, water filtration, and sediment stabilization.

Recognition of links between the ecosystems mangroves, seagrasses and reef

Notion of trophic cascades due to changes in abundance of sea urchins, leading to overgrazing of seagrasses with potential effects on inshore fisheries.

Acknowledgement by respondents that seasonal climatic changes affect the distribution and abundance of shrimp and finfish in the area:

Seasonal monsoons and the resulting freshwater outflow attract juvenile shrimps into the mangrove system.

Seasonal monsoon related wind patterns and currents affect fish migrations along the regional coastline.

\section{All groups}

Deep Sea

Speargun*

Seine net

All groups

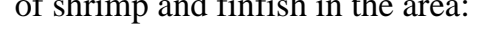

Local climatic, hydrologic, edaphic, and geomorphologic factors as well as biotic interaction strongly affect ecological processes and the abundance and distribution of species at any one place.
Species interacting species have key, broadscale ecosystem-level effects. 
Disturbance

The type, intensity, and duration of disturbance shape the characteristics of populations, communities, and ecosystems.
Notion among some fishing groups that sea urchin aggregations can affect the dynamics of seagrass meadows and associated fauna.
Speargun*

Seine net
Acknowledgement that historical and present landuses such as mangrove cutting will cause changes in e.g., crabs, shrimp, fish, and ecosystem functions such as soil stabilization, water movement, nursery habitats, nesting areas, and wind breakers. the distribution and abundance of associated species,

Shrimpers

Deep Sea

Speargun

Seine net

Gillnet

Middlemen

Farmers*

Businessmen*

Notion among some fishing groups that changes in climate, e.g., timing of the monsoon rains and El Niño phenomena, have occurred recently resulting in an effect on the artisanal shrimp fishery as well as mangrove coverage

Awareness of the nursery function provided by mangroves for fish and shellfish residing part of their life outside of the mangrove habitat. Shows a notion of the positive spillover effect of such functions on coupled ecological subsystems such as seagrass beds and coral reefs.
Shrimpers

Deep Sea

Speargun

Seine net

Gillnet
Shrimpers

Deep Sea

Speargun

Seine net

Gillnet

Middlemen

Farmers*

Businessmen* have unquestionably decreased. One cause put forth by seine netters for the decline in fish stocks was a recent sea urchin infestation, and overgrazing resulted in the complete removal of large areas of seagrass in the bay. Such grazing aggregations of sea urchins have been observed in the Mombasa lagoon, north of the study area (Alcoverro and Mariani 2002), and the potential for such aggregations to dramatically reduce seagrass or algal cover is well documented (Sala et al. 1998, see also Valentine and Heck 1999 for review). It has been proposed that sea urchin aggregations are caused by highly successful recruitment (Rose et al. 1999) and anti-predatory benefits from dense aggregations, in combination with reduced predation pressure from known predators such as triggerfish (Balistidae) (McClanahan and Shafir 1990, Alcoverro and Mariani 2002). Intense fishing pressure in the area has drastically reduced fish populations in general and triggerfish populations in particular (McClanahan and Obura 1995). It is likely that high sea urchin abundance may suppress recovery of fish populations because several of the targeted species are herbivores and compete with urchins for resources (McClanahan et al. 1994). The link between urchins, seagrasses, and fishery was not acknowledged by any other occupational category.

All but one category of fishermen, i.e., handliners, had a good understanding of the ecological link between mangroves and juvenile fish and shrimps (Table 2), whereas farmers and businessmen had consistently vague conceptions of these links. However, when asked to elaborate on the life history and specific ecological traits of shrimps, the responses differed. All of the fishermen, exceptthe handline fishermen, claimed that shrimp enter the system as juveniles during the seasonal rains. The speargun fishermen and the women insisted on a markedly limited distribution compared to the other groups, along with farmers and businessmen. 
A similar discussion took place on crabs, another major ecological component of the system. Knowledge of crabs and swimming crabs of commercial importance Scylla serrata and Portunus pelagicus was similar across all fishing groups with the exception of speargun and handline fishermen who had slightly vaguer ideas of life history traits, and nonfishing groups who showed a poor perception of these issues. Of all respondents, only two of the middlemen recognized the pelagic life stage of the crab life cycle. One of these men had previously worked for a fisheries researcher in the area, which may account for his more detailed knowledge. The other man could not recall where he had heard this, nor could he ascertain its accuracy.

A concluding discussion on the effect of mangrove deforestation was conducted to investigate knowledge of ecological links between mangroves and surrounding ecosystems. Most of the groups had a clear understanding of the importance of mangroves as nursery areas for fish and shellfish. Only one group, the handline fishermen, did not see any connection between the loss of mangroves and the fisheries. It is possible that this is because they target large predatory fish, and they are not thinking directly about the the mangrove resources. Interestingly, although showing an understanding of the ecological importance of mangroves, neither of the net fishing groups could perceive any threats of mangrove loss to their fishery, despite the fact that some of their target species are clearly linked to the mangrove-lagoon habitat.

Although all fishing-related groups stressed the importance of mangroves for the direct goods and services they supply, only the women mentioned medicinal and religious uses. Farmers and businessmen had difficulties describing any related benefits, apart from the nursery function and reduced soil erosion.

Perceptions of mangrove coverage from an historical perspective differed substantially between groups, but over $70 \%$ of the fishing related groups mentioned that El Niño was a factor that caused the deaths of many mangroves. Most attributed it to fresh water dilution, whereas others attributed it to high temperatures. No published records exist on the effect of El Niño on the mangroves in the area, but several larger stands in the bay were severely affected in 1998 by sedimentation and oxygen depletion (Kairo, personal communication). Nonfishing groups had poor perceptions of both the changes in mangrove coverage and the potential causes of these changes.

The belief component is often cited as an important component in LEK and TEK (see Berkes et al. 1995, or Olsson and Folke 2001, respectively). In this study, many respondents exhibited a mix of knowledge based on practical observations, knowledge acquired through training, and religious beliefs. For example, the religious aspect was most prominent among some of groups of net fishermen who ascribed fluctuations in fish catches to the will of God as illustrated by the following quote:

"Changes in fish catch are dependent on God's will. God can remove one species and transfer it to another place. Looking at fish stocks as declining or increasing is a human way of looking at it. It does not work that way, it's God's will."

\section{DISCUSSION}

Analysis revealed that local ecosystem knowledge (LEK), held by respondents, ranged from detailed accounts of feeding of certain target species to acknowledgement of large-scale climatic changes affecting shrimp stocks and mangrove coverage. However, answers, in general, revealed a fragmented view of the seascape, and at present this appeared to be more related to maximization of resource extraction than to a deep understanding of ecological processes and causal links. Whether acknowledgement of such links previously existed, but were not essential to successfully extract resources due to lower fishing pressure, cannot be fully explored here. The patterns are nevertheless supported by the present day lack of enforced taboos, closed seasons, or exempted target species. The patterns are also supported by the lack of formalized knowledge transfer, resulting in poor coordination of knowledge and fragmented transfer over generations. Knowledge common to all groups included acknowledgement of the central role played by mangroves for coastal protection, water quality, and nursery habitat. The seasonal rains and related freshwater pulse affecting shrimp migrations were also recognized by all respondents, although at varying levels of detail (Fig. 3). Table 2 lists the five principles defined as important for ecosystem management by Dale et al. (2000) as well as the knowledge of local resource users reflecting each principle. Based on the information in Table 
2, some differences can be discerned between groups with respect to the level of detail of ecological links and processes, the notions of the temporal and spatial scale of these processes, and their effects on ecosystem functioning (Fig. 3). The following section will highlight these differences and discuss potential factors affecting the knowledge distribution among groups as well as its implications for the use of LEK in future management initiatives.

\section{Heterogeneous knowledge distribution among gear-defined groups}

Handline fishermen and nonfishers had a comparatively poor perception of the effect of climate on mangrove coverage and shrimp recruitment, whereas other respondents mentioned that heavy rains, freshwater outflow, and extreme temperatures associated with El Niño in 1998 were principal causes. Of the handline fishermen interviewed, only one had stayed permanently in the area for more than five yr, which explains why he had difficulty in seeing an effect of climate mangrove coverage. The fact that they target pelagic species and focus fishing effort in the outer part of the seascape (Fig. 2) may also reflect thier lack of insight regarding shrimp migration and distribution in the bay. That fishermen are familiar with the El Niño phenomena at all is most likely attributable to the fact that some of them were involved as labor in mangrove replanting initiatives in the area. In addition, an information meeting was held in the village to describe the effects of the $1998 \mathrm{El}$ Ninõ on the mangroves of the area.

Juvenile penaeid shrimps are the sole target species of fishing women. Any other fish caught is merely by-catch. Women also move in a limited area of the bay when fishing (Fig. 2) because most of them cannot swim and are restricted to shallow channels along the mangrove fringe where they use handheld scoop nets. Consequently, they had a restricted view of the seascape (Fig. 3). Even the perceived distribution and life history patterns of their main target species, i.e., shrimp, were limited compared to other fishing groups because they, like most other groups, base this knowledge solely on personal experience and observation. Speargun fishermen and nonfishers shared this view of distinctly limited shrimp distributions. Speargunners move over a much larger area of the lagoon than do the women (Fig. 2), but they target lobster or larger fish on the reef or in nearby seagrass beds. This occupational category is also one of the fastest expanding groups in the area (McClanahan et al. 1997) due to the fact that many enter the profession as a last resort requiring little, if any, prior training or apprenticeship (Glaesel 2000). This may explain their less holistic view of the bay system compared to other fisher groups.

The deep-sea fishermen, and to some extent the seine-net fishermen, exhibit the broadest notion of system dynamics, acknowledging processes that occur on larger spatial and temporal scales such as regional fish migrations and climatic phenomena, including El Niño, which affect mangrove coverage through changes in rainfall. Captains, heading large netting crews in deep waters, carry a large responsibility and enjoy a high status among fishermen, which is related to their perceived expertise. Such expertise is largely based on their good understanding of both biological and physical processes relevant for resource extraction including winds, currents, and weather patterns, which partly explains why groups headed by knowledgeable captains recognize ecological processes at larger scales than other groups, such as spear gunners who work alone and women who are based solely inside the lagoon. The fact that deep-sea and seine-net fishermen did not perceive any large, long-term changes in fish catches may be because they fish outside the reef, targeting more pelagic fish stocks that are sustained through population dynamics at a larger scale than the local seascape (Table 2) or because of religious beliefs, as shown previously. Unfortunately, analysis of the extent to which religion influences the worldview and perceptions of ecological processes of respondents lies outside the scope of this paper. The links between religious beliefs, worldviews, and LEK may be complex, but should be further studied to discern how they affect the conception of ecological knowledge and understanding.

Interestingly, seine-net groups, with a strong focus on the lagoon (Fig. 2), were the only ones to acknowledge the interactions between sea urchin population explosions, declining seagrass meadows, and fish abundance observed in the area. This indicates that the link between seagrass coverage and some targeted fish species such as Siganus sutor (African whitespotted rabbitfish) and Leptoscarus vaigiensis (Seagrass parrotfish) are recognized. It also supports the idea that geographic location within the seascape will affect the type of 
knowledge accumulated by fisher groups, because it is largely based on observations at a very local scale. Furthermore, this explains why deep-sea and handline fishermen did not perceive this link. However, reasons for the sudden rise in sea urchin density could not be established by the seine-net fishermen. From a scientific point of view, drastic increases in sea urchin populations along the coast are believed to be caused by stock depletion of predators such as red-lined triggerfish (Balistapus undulates) and triple tail wrasse (Cheilinus trilobatus), among other things (McClanahan and Shafir 1990, McClanahan 1995, Alcoverro and Mariani 2002). Interestingly, neither of the groups interviewed mentioned triggerfish nor large wrasses as targeted species. This could be an effect of the interview setup, but it may also reflect the presemt low abundances of these species in the area as previously documented (McClanahan and Obura 1995).

The diets of the fish that were reported by many of the groups concurred fairly well with available scientific information. However, at a very general level, these reports were based on observations of gut content. Knowledge of fish diets is important ecological information, but based solely on observations of gut contents, it is likely to reflect only a select part of the items ingested by fish with a bias toward slowly degrading food items. This may affect perception of trophic linkages in the system and could explain why fishermen did not acknowledge the most probable cause of increasing urchin densities, i.e., a lack of predation. Another reason such knowledge is not widespread among fishers could be a loss of social memory among the active generation with respect to the ecological functions maintained by predatory fish, provided that such knowledge previously existed. Lack of institutions for knowledge exchange in combination with influx of migrant and unskilled fishermen, as in the case of many deep-sea fishermen and speargunners, respectively, may also have contributed to the apparent knowledge dilution and memory loss after stock depletion. Although on different scales, parallels could be drawn between this observed pattern and the shifting baseline syndrome described by Pauly (1995). It means that new generations inappropriately base their evaluation of change in fish stocks and species composition on the levels existing at the time of their own entry into the profession, potentially masking gradual resource depletion.

\section{Demographic changes influencing the nature of local ecological knowledge}

As in the community studied here, heterogeneity in knowledge distribution among resource user groups has been observed elsewhere (Ferguson and Messier 1997, Ghimire et al. 2004), and suggested implications for management include effects on communal views of system function as well as consensus with regards to the resource status (Ghimire et al. 2004, Moller et al. 2004). Capturing and comparing knowledge of different individuals and groups is inherently tricky, but with methods designed to minimize error, this paper nevertheless hopes to give an accurate representation of the body of LEK existing in the village. Given this, results show varying quality, i.e., level of detail, of group LEK related to the spatial user pattern of respective groups. Groups involved in resource extraction in a limited area of the seascape, e.g., shrimpers and handliners, have a higher level of LEK related to that particular subsystem but less detailed LEK for the other subecosystems (Fig. 3). At the same time, groups with larger spatial range as well as overlap in spatial distribution, such as the net fishermen (Fig. 2), have remarkably higher and similar levels of detail in LEK for each subecosystem, even though the exact knowledge described, in turn, related to their main target species, might vary from group to group.

Several gaps of knowledge common to many groups are also observed. These gaps are related to scale and ecological linkages, including a poor understanding of fish migrations, life history patterns and migrations, divergent views on historical mangrove coverage, and a lack of insight into trophic linkages. In addition to group-specific localized fishing efforts, this could be explained by patterns of recent immigration, changes in the status of the fishing profession, and increasing numbers of young, unskilled fishermen entering certain occupational categories. Recent immigration and the flexible or transient nature of the residence status of many Tanzanian fishermen in the village is likely to have an effect on the time horizons with which they view their resource consumption, as well as the social memory of ecological processes based on past experience of local events mentioned earlier.

Remittances often allow for the substitution of goods and services previously extracted from the nearby environment, and may result in a reduced appreciation of the need for common property 
resource conservation (Naylor et al. 2002). Although only $25 \%$ of village households report receiving such subsidies, the combination with substantial immigration may have served to erode LEK in the area. Historically, traditional Digo fisheries management included sacred sites, restrictions on gear use, fish size, and fishing periods, as well as fees for foreign fishers to access the fishing grounds (McClanahan et al. 1997). The past effectiveness of this traditional enforcement is not known. However, today it is limited, largely due to immigration and a belief among young fishers that such practices go against Islam. Changes in demographic structures and shifting belief systems are bound to have had a strong impact on the pool of LEK in the area. One can only speculate to what extent traditional management included a deeper understanding of causal ecological links by comparing with similar traditional management systems in other parts of the world (Johannes 1981, Aswani and Hamilton 2004), but it appears that current LEK is primarily used for maximizing resource extraction as seen through the strong correlation between gear, group knowledge, and target species. This could create a self-enforcing state of declining holistic knowledge and an increasing decoupling from, and responsibility for, the communal resource. The somewhat fatalistic religious views expressed by many respondents with respect to fish stocks are another example that may have an effect on incentives to conserve and, thus, for community based management.

\section{Combining local ecological knowledge and scientific knowledge for improved resource management}

Although a large body of ecological knowledge exists within the fishing community at hand, it is clear that certain limitations exist in identifying trends of ecological change at scales important for sustainable management. In a review of the strengths and weaknesses of local vs. scientific ecological knowledge, Moller et al. (2004), nevertheless, point to the positive effects of combining the two knowledge systems for more effective resource monitoring and management. For example, they suggest that although science can offer the advantage of decoupling the sampling from harvests and provide studies of causation, inclusion of LEK can supplement science by increasing sample size and time series, helping in the formulation of useful scientific hypotheses (Neis et al. 1999). Both knowledge systems suffer from the difficulty in capturing cross-scale linkages, but combinations of the two may reduce uncertainties. Although LEK is often poor at detecting shifts in average patterns of ecological parameters that may be more relevant or signal different concerns than extreme events, science is likely to miss occasional extreme events, i.e., those captured by daily local observations, due to short sampling duration (Moller et al. 2004). The recognition by fishermen of extreme climatic events such as El Niño and its effect on reefs, shrimp populations, mangroves, and seagrass coverage, is one example. Their poor recognition of declining fish stocks and differing scales of fish migrations, and lack of insight into causal relationships affecting the status of the seagrass meadows are also good examples of the potential for complementarities in combining science and LEK in this community. In a case study of the Ibiraquera Lagoon, Seixas and Berkes (2003) identified factors weakening the resilience of the coupled social-ecological system. Breakdown of traditional institutions, rapid technological change in the form of spearguns and nylon nets, as well as rapid changes in the local socioeconomic system by immigration all qualify as such factors and have been identified in this study. In combination with reported overfishing, this indicates a system heading down a potentially negative trajectory. Key factors proposed to counterbalance this include cross-scale communication, sharing of facts about resource status, and comanagement using scientific and local knowledge as a source of novelty and innovation (Seixas and Berkes 2003). LEK, held by occupational groups in the studied community, indicates a base on which to build such information exchange and may provide a source of resilience for the social-ecological system at hand, provided that gaps in LEK and links to scales of ecological processes are addressed, and that the direct link between gear, i.e., occupational categories, and certain ecological functions are jointly recognized by resource users.

Initiatives for comanagement are stirring in the area of coastal zone management in Kenya, and whereas LEK should be viewed as a base to build on and involve stakeholder groups, it is important to evaluate the strengths and weaknesses of such information to identify at which level scientific information can best complement existing knowledge. In a system in which trust between scientists and local stakeholders has sometimes been under severe strain as a result of historical 
dealings between resource users and government agencies (McClanahan et al. 1997, Alidina 2005), it is important to find points of convergence; areas in which science and LEK can meet and trust between local stakeholders and scientists can be built upon by mutual learning and exchange of information to enhance resource management. This will promote ownership into the management process and assessment of resource status among stakeholders (Neis et al. 1999). This study has identified a number of such areas as well as gaps of information in which science can play an important, complementary role for sustainable management of coastal resources. The next step is to identify a forum in which this exchange of information can take place on a continuous basis to allow for the accumulation of LEK for improved management. The Diani Chale Management Trust (DCMT) in Diani-Chale, a local institution with an emerging mandate to address resource management issues and an active collaboration with the scientific community through Coral Reef Degradation in the Indian Ocean (CORDIO), is a good example of such a forum. Similar arrangements in this village and other fishing communities that currently lack strong local institutions could facilitate the process. The recently started Fishermen's Group, initiated by local fishermen, could perhaps be such a starting point and a step in the direction to increase and enhance local ecological information and social memory. This could help improve the knowledge pool in light of further socioeconomic and demographic changes and as such enhance the adaptive capacity of future management systems.

\section{CONCLUSION}

This study shows that content and detail of ecological knowledge of occupational groups varies and can be linked to gear use. Furthermore, analysis suggests that the knowledge may be based more on incentives to extract than on those to conserve, as no institutions have developed a method for the transfer of knowledge related to sustainable use or critical ecological functions. The social-ecological system at hand suffers from many of the problems associated worldwide with chronic poverty such as increasing population pressure, high unemployment, and degradation of natural resources. However, based on results presented here, investments geared at enhancing socioeconomic standard, e.g., through investment in improved gear, run the risk of further propelling the system down the poverty trap through habitat degradation and stock depletion, if not simultaneously combined with enhancement of existing LEK. Science may have an important role to play in this case, but based on experience, careful consideration of how this dialogue should proceed is advised. Investment in institutions for knowledge exchange that are credible and owned by all involved parties must be initiated prior to or in conjunction with any future investments to boost the social system based on marine resource extraction.

Responses to this article can be read online at:

http://www.ecologyandsociety.org/voll1/iss 1/art32/responses/

\section{Acknowledgments:}

The author would like to thank all respondents for their participation in the study. Acknowledgements also go to the work of field assistants P. Kimani and A. Rashid without whose work and organizational skills this study would not have been possible. The study was conducted with financial support from SIDA (Swedish International Development and Aid) and through affiliation by the author to Kenya Marine and Fisheries Research Institute in Mombasa, Kenya. Finally, I also thank two anonymous reviewers for constructive comments that greatly improved this paper.

\section{LITERATURE CITED}

Agrawal, A. 1997. Community in conservation: beyond enchantment and disenchantment. Conservation and Development Forum, Gainsville, Florida, USA.

Alcoverro, T., and S. Mariani. 2002. Effects of sea urchin grazing on seagrass (Thalassodendron ciliatum) beds of a Kenyan lagoon. Marine Ecology Progress Series 226:255-263.

Alidina, H. 2005. Local level fisheries management in Diani-Chale, Kenya: current status and future directions. Coastal Management 33(4):459-470.

Aswani, S., and R. J. Hamilton. 2004. Integrating indigenous ecological knowledge and customary 
sea tenure with marine and social science for conservation of bumphead parrotfish (Bolbometopon muricatum) in the Roviana Lagoon, Solomon Islands. Environmental Conservation 31(1):69-83.

Becker, C. D., and K. Ghimire. 2003. Synergy between traditional ecological knowledge and conservation science supports forest preservation in Ecuador. Conservation Ecology 8:1.

Becker, C. D., and E. Ostrom. 1995. Human ecology and resource sustainability: the importance of institutional diversity. Annual Review of Ecology and Systematics 26:113-133.

Berkes, F., C. Folke, and M. Gadgil. 1995. Traditional ecological knowledge, biodiversity, resilience, and sustainability. Pages 281-299 in C. A. Perrings, K. G. Mäler, C. Folke, B. O. Jansson, and C. S. Holling, editors. Biodiversity Conservation. Kluwer Academic Press, Dordrecht, The Netherlands.

Berlin, B. 1973. Folk systematics in relation to biological classification and nomenclature. Annual Review of Ecology and Systematics 4:259-271.

Christensen, N. L., A. M. Bartuska, J. H. Brown, S. Carpenter, C. D'Antonio, J. F. Francis, J. A. MacMahon, R. F. Noss, and D. J. Parsons. 1996. The report of the Ecological Society of America committee on the scientific basis for ecosystem management. Ecological Applications 6:655-691.

Colding, J., and C. Folke. 2001. Social taboos: "invisible" systems of local resource management and biological conservation. Ecological Applications 11(2):584-600.

Dahdouh-Guebas, F., C. Mathenge, J. G. Kairo, and N. Koedam. 2000. Utilization of mangrove wood products around Mida Creek (Kenya) amongst subsistence and commercial users. Economic Botany 54(4):513-527.

Dale, V. H., S. Brown, R. A. Haeuber, N. T. Hobbs, N. Huntly, R. J. Naiman, W. E. Riebsame, M. G. Turner, and T. J. Valone. 2000. Ecological principles and guidelines for managing the use of land. Ecological Applications 10(3):639-670.

Davis, A., J. M. Hanson, H. Watts, and H. MacPherson. 2004. Local ecological knowledge and marine fisheries research: the case of white hake
(Urophycis tenuis) predation on juvenile American lobster (Homarus americanus). Canadian Journal of Fisheries and Aquatic Science 61:1191-1201.

Davis, A., and J. R. Wagner. 2003. Who knows? On the importance of identifying 'experts' when researching local ecological knowledge. Human Ecology 31(3):463-489.

de La Torre-Castro, M., and P. Rönnbäck. 2004. Links between humans and seagrasses: an example from tropical East Africa. Ocean and Coastal Management 47:361-387.

Dietz, T., E. Ostrom, and P. C. Stern. 2003. The struggle to govern the commons. Science 302:1907-1912.

Drew, J. 2005. Use of traditional ecological knowledge in marine conservation. Conservation Biology 19(4):1286-1293.

Ferguson, M. A. D., and F. Messier. 1997. Collection and analysis of traditional ecological knowledge about a population of arctic toundra caribou. Arctic 50(1):17-28.

Froese, R., and D. E. Pauly. 2004. Fishbase. World Wide Web electronic publication. Version (06/2004). Available online at: http://www.fishbase. org.

Ghimire, S. K., D. McKey, and Y. AumeeruddyThomas. 2004. Heterogeneity in ethnoecological knowledge and management of medicinal plants in the Himalayas of Nepal: implications for conservation. Ecology and Society 9:3.

Glaesel, H. 1997. Fisher, parks and power: the socio-environmental dimentions of marine resource decline and protection on the Kenya coast. Dissertation. University of Wisconsin-Madison, Madison, Wisconsin, USA.

Glaesel, H. 2000. State and local resistance to the exapnsion of two environmentally harmful marine fishing techniques in Kenya. Society and Natural Resources 13:321-338.

Government of Kenya (GOK). 1991. The Fisheries Act, Chapter 378. Government of Kenya, Nairobi, Kenya.

Government of Kenya (GOK). 1994. Kenya 
forestry master plan. Ministry of Environment and Natural Resources, Nairobi, Kenya.

Government of Kenya (GOK). 2001. The Fisheries Act, Chapter 378: Susidiary legislation. Government of Kenya, Nairobi, Kenya.

Goldman, M. 2003. Partitioned nature, privileged knowledge: community-based conservation in Tanzania. Development and Change 34(5):833-862.

Hulme, D., and M. Murphree. 1999. Communities, wildlife and the "new conservation" in Africa. Journal of International Development 11:227-285.

Johannes, R. E. 1981. Word of the lagoon: fishing and marine lore in the Palau district of Micronesia. University of California Press, London, UK.

Johannes, R. E. 1998. The case for data-less marine resource management: examples from tropical nearshore fisheries. Trends in Ecology and Evolution 13:243-246.

King, A. 2000. Managing without institutions: the role of communication networks in governing resource access and control. Dissertation. University of Warwick, Warwick, UK.

McClanahan, T. R. 1995. Fish predators and scavengers of the sea urchin Echinometra mathaei in Kenyan coral reef marine parks. Environmental Biology of Fishes 43:187-193.

McClanahan, T. R., H. Glaesel, J. Rubens, and R. Kiambo. 1997. The effects of traditional fisheries management on fisheries yields and the coral-reef ecosystems of southern Kenya. Environmental Conservation 24(2):105-120.

McClanahan, T. R., M. Nugues, and S. Mwachireya. 1994. Fish and sea urchin herbivory and competition in Kenyan coral reef lagoons: the role of reef management. Journal of Experimental Marine Biology and Ecology 184(2):237-254.

McClanahan, T. R., and D. O. Obura. 1995. Status of Kenyan coral reefs. Coastal Management 23:57-76.

McClanahan, T. R., and S. H. Shafir. 1990. Causes and consequences of sea urchin abundance and diversity in Kenyan coral reef lagoons. Oecologia
83:362-370.

Moller, H., F. Berkes, P. O'Brian Lyver, and M. Kislalioglu. 2004. Combining science and tradtitional ecological knowledge: monitoting populations for co-management. Ecology and Society 9:3.

Morgan, D. L. 1998. Planning focus groups. Sage, London, UK.

Naylor, R. L., K. M. Bonine, K. C. Ewel, and E. Waguk. 2002. Migration, markets, and mangrove resource use on Kosrae, Federated States of Micronesia. Ambio 31(4):340-350.

Neis, B., D. Schneider, L. Felt, R. Haedrich, J. Fischer, and J. Hutchings. 1999. Fisheries assessment: what can be learned from interviewing resource users? Canadian Journal of Fisheries and Aquatic Science 56:1949-1963.

Ng'weno, B. 1995. Reinventing ground rules: inheritance of land among the Digo of Southern Kenya. Thesis. Stanford University, Stanford, California, USA.

North, D. C. 1990. Institutions, institutional change and economic performance: political economy of institutions and decision. Cambridge University Press, Cambridge, UK.

Obura, D., S. Wells, J. Church, and C. Horrill. 2002a. Monitoring of fish catches by local fishermen in Kenya and Tanzania. Marine and Freshwater Research 53:215-222.

Obura, D. O., I. N. Wanyoni, and J. M. Mwaura. $2002 b$. Participatory monitoring of an artisanal fishery in Kenya. Pages 70-82 in O. Lindén, D. Souter, D. Wilhelmsson, and D. Obura, editors. Coral reef degradation in the Indian Ocean (CORDIO), Status report 2002. University of Kalmar, Kalmar, Sweden.

Ochiewo, J. 2004. Changing fisheries practices and their social implications in south coast Kenya. Ocean and Coastal Management 47:389-408.

Ogden, J. C., and H. E. Gladfelder. 1983. Coral reefs, seagrass beds, and mangroves: their interactions in the coastal zone of the Caribbean. UNESCO Reports in Marine Science Number 23. UNESCO, Montevideo, Uraguay. 
Olsson, P., and C. Folke. 2001. Local ecological knowledge and institutional dynamics for ecosystem management: a study of Lake Racken Watershed, Sweden. Ecosystems 4(2):85-104.

Ostrom, E. 1990. Governing the commons: the evolution of institutions for collective action. Cambridge University Press, Cambridge, UK.

Ostrom, E. 2005. Understanding institutional diversity. Princeton University Press, Princeton, New Jersey, USA.

Pauly, D. 1995. Anecdotes and the shifting baseline syndrome of fisheries. Trends in Ecology and Evolution 10:430.

Putnam, R. D. 1993. Making democracy work: civic traditions in modern Italy. Princeton University Press, Princeton, New Jersey, USA.

Rose, C. D., W. C. Sharp, W. J. Kenworthy, W. G. Hunt, W. G. Lyons, E. J. Prager, J. F. Valentine, M. O. Hall, P. E. Whitfield, and J. W. Fourqurean. 1999. Overgrazing of a large seagrass bed by the sea urchin Lytechinus variegates in Outer Florida Bay. Marine Ecology Progress Series 190:211-222.

Sala, E., C. F. Boudouresque, and M. HarmelinVivien. 1998. Fishing, trophic cascades, and the structure of algal assemblages: evaluation of an old untested paradigm. Oikos 82:425-439.

Scoones, I. 1999. New ecology and the social sciences: what prospects for a fruitful engagement? Annual Review of Anthropology 28:479-507.

Seixas, C. S., and F. Berkes. 2003. Dynamics of social-ecological changes in a lagoon fishery in southern Brazil. Pages 271-298 in F. Berkes, J. Colding, and C. Folke, editors. Navigating socialecological systems: building resilience for complexity and change. Cambridge University Press, Cambridge, UK.

Tobisson, E., J. Andersson, Z. Ngazi, L. Rydeberg, and U. Cederlöf. 1998. Tides, monsoons and seabed: local knowledge and practice in Chwaka Bay, Zanzibar. Ambio 27(8):677-685.

Valentine, J. F., and K. L. J. Heck. 1999. Seagrass herbivory: evidence for the continued grazing of marine grasses. Marine Ecology Progress Series
176:291-302.

World Resources Institute (WRI). 2005. World Resources 2005: the wealth of the poor-managing ecosystems to fight poverty. World Resources Institute in collaboration with UNDP, UNEP, and World Bank, Washington, D.C., USA.

Young, O. R. 2002. The institutional dimensions of environmental change: fit, interplay, and scale. MIT Press, Cambridge, UK. 
APPENDIX 1. Additional description of methodology and data collection

\section{Attributes of occupational categories}

Nine different occupational categories were identified; businessmen (local entrepreneurs), farmers, middlemen and six occupational categories of fishermen (and women) defined based on primary gear type and fishing technique. Businessmen is a rather broad occupational category, which was defined based on a description by respondents of their livelihood as selling and/or buying any kind of goods such as food, groceries, building material and related services. Middlemen is the local term used for fishmongers, persons who buy fish from the fishermen directly at the landing sites and sell it on to a third party. Because their business is purely focused on fish they were distinguished from other businessmen. Furthermore, many middlemen were previously fishermen, a factor judged to potentially affect their LEK, wherefore they were separated as a distinct category. All fishing groups were defined by gear and respondents were included in each respective focus group category based on their reported primary occupation.

Focus groups were selected through interviews with the village chairman and fishermen at the local landing site in combination with validation of occupation among members of the community through data collected during a parallel study of social network(Crona and Bodin forthcoming). Due to his informal but central position, which provides him with in-depth knowledge of most households in the village, the chairman was approach and asked to identify as many persons as possible from each gear defined category. These persons were then approached at the local landing site and asked to further identify people from each category. All names were then cross-checked against the database on selfreported primary occupation gathered for the parallel study in an attempt to validate occupational membership. This was done as some fishermen may employ several techniques depending on season, although most will identify with one specific gear type when asked to state their primary occupation. From this list of names persons were then approach at random. For logistical reasons most often a captain was approached and asked to participate along with members of his crew. Most fishermen spend long hours out at sea and it became apparent that to gather random members of separate crews for each focus group was nearly impossible as each crew operate on their own schedule.

\section{The interview set-up}

The comparative advantages of individual versus group interviews vary depending on the purpose of the investigation. The use of focus groups in this study was motivated by several factors. First, focus groups provide interviewers with the ability to study interaction on a given topic, enhancing understanding of not only what participants think but also why they think this way (Morgan 1988). In this case I believed such interaction among fishermen in a group could lead to more elaborate, in depth information on ecosystem processes and could assist participants in formalizing their ideas. It also allowed me to observe group dynamics thereby evaluating to what extent captains potentially dominated the discussion. This appeared not to be the case wherefore results are judged to be representative of the entire group interviewed. Secondly, previous interaction among researchers, villagers and government officials in the area regarding management issues have shown that group discussion can be more productive than individual interviews as they enhance the confidence of individuals to speak their mind. Such lack of confidence may stem from the inherent hierarchical positioning of the researcher and the respondent in a one-on-one situation due to ethnic, cultural as well as educational differences. Focus groups reduce the interaction with the interviewer and puts greater emphasis on inter-group communication (Morgan 1988).

All focus group interviews were conducted using a moderator (a Kiswahili speaking male scientist knowledgeable with respect to the nature of local fishing operations, target species and ecological characteristics of the bay). The author (conversant in Kiswahili but not entirely fluent) introduced the objective and set-up of the interview in Kiswahili and was present throughout the interview to help guide the process and follow up on specific questions of interest. In addition a translator was present to 
translate and clarify any issue that was not entirely clear to the author. The same set-up was used for interviews with women but in these cases more emphasis was placed by the author (also a woman) on the introduction and objectives of the interview to encourage the women to share their views and instill confidence.

Below is outlined the semi-structured interview guideline used for all interviews in the study:

\section{Interview guideline}

\section{Introduction}

Q: Let me ask, are you all from this village? (Respondents were asked to state their names, where they live, and for how long)

Q: How long have you been fishing (farming, doing business etc) in this area?

Q: Could you tell me a little about how and why each of you became a fisherman? (The question was asked to give a brief personal history of each group member)

Depending on the answers this was followed up with...

Q: Is that a common way of entering the profession?

Q: Does this mean that your sons/children will become fishermen as well? (The question was asked to give an indication of a potential changes in traditions, knowledge transfer and young people moving from village)

Q: How will all the knowledge you have be passed on to younger generations?

Q: Do you feel confident that the knowledge will be kept this way?

Q: Is it important that such knowledge is maintained and passed on to younger generations?

\section{Topic 1- Knowledge of species and ecological processes in the bay}

Q: Did you get a good catch today? What did you catch?

Q: Do you always catch this type of fish? If not what else do you normally catch? (A discussion around a representative composition of catch in terms of different species)

Q: Respondents were asked to identify the 10-15 most important fish species they catch taking into consideration the anticipated price at sale, the perceived abundance and the proportional importance of the species to their daily catch.

Q: Out of these 10-15, which 5 species do you judge to be the most important (based on anticipated price at sale, the perceived abundance and the proportional importance of the species to their daily catch)?

Q: Could you explain to me how the catch changes over the course of the year, from season to season, fort each of these five taxa/species?

Q: For each of the 5 taxa/species:

- Where do you catch it? At what time/season? Why?

- Are they adults?

- What about when they are young, where can you find them? Why?

- What do these fish eat at different stages of their life?

At this point the group was asked to draw a rough map of the area together with the interviewer. Specific sites and characteristic features on the map were discussed to ensure that the interviewer's perception of the area map agreed with the one held by the group. All group members were encouraged to get involved in the process. The map was then used to indicate primary target areas for the taxa/species identified in the previous questions. 
Q: Do you use any bate when fishing? Where does it come from and how/why?

Q: Respondents were asked to identify 3 taxa/species of fish that they associate primarily with A) mangroves B) sea grass beds $\mathrm{C}$ ) reefs.

(This question was used partly as a validation tool for knowledge of target species above but also as a measure of the how easily respondents of non-fisher categories could differentiate between fish taxa associated with different sub-systems of the coastal seascape)

Throughout the above discussion respondents were probed for clarifications and further explanations wherever appropriate and needed.

\section{Shrimps}

Q: Do shrimps come in the mangroves?

Q: If so why are they found in the mangroves?

Q: Are they big or small when they come in?

Q: Where (in the bay) are shrimps caught? Why?

Crabs

Q: Where do they live? And why?

Q: Do they live their whole life there? Explain. (The question was asked to reveal knowledge of the crab life cycle).

Q: What do you think would happen if most of the mangroves around the bay were cut down? Would it have any effect on the fisheries? If so, how? Do you know of any other effects of mangrove deforestation?

Topic 2- Acknowledgment of changes in the ecosystem over time and understanding of ecological processes and links among components in the system

Q: You say you have been fishing in the area for X years, have you noticed any changes in the type of fish/shrimps/crabs you catch or the area where fish/shrimp/crabs are caught?

Using of the map drawn previously to explain changes and patterns the following questions were asked: Q: Have you perceived any change in mangrove coverage over the years? A discussion about coverage before, during and after the change (historical events were used to place the change in time).

Respondents were asked to explain the process of change by drawing a time line indicating patterns of increasing and decreasing coverage over time.

Q: Have you perceived any change in catches over the years? Respondents were asked to identify any changes in fish catches over time by drawing a time line (with assistance from the interviewer and moderator) and indicating patterns of increasing and decreasing catches over time.

Q: Can you tell me what you think may be the reason for this change?

Q: What solutions/actions can you suggest to improve the situation? (This was asked in order to further identify coupled social-ecological knowledge and ideas, i.e. recognition of institutional/organizational change needed for resource management)

Throughout the above discussion specific questions to follow up issues of importance were incorporated under each topic.

\section{Literature cited:}

Crona, B. I., and Ö. Bodin. forthcoming. What you know is who you know? Patterns of communication as prerequisites for co-management. Ecology and Society.

Morgan, D. L. 1988. Focus groups as qualitative research. Sage Publications Inc., Beverly Hills, CA. 
Ecology and Society 11(1): 32

http://www.ecologyandsociety.org/vol11/iss1/art32/ 